MRR, Taguchi PSI method, surface roughness, cylindrical grinding process

\author{
Dung Hoang TIEN ${ }^{1^{*}}$ \\ Do Duc TRUNG ${ }^{1}$ \\ Nguyen Van THIEN ${ }^{1}$ \\ Nhu-Tung NGUYEN ${ }^{2}$
}

\title{
MULTI-OBJECTIVE OPTIMIZATION OF THE CYLINDRICAL GRINDING PROCESS OF SCM440 STEEL USING PREFERENCE SELECTION INDEX METHOD
}

\begin{abstract}
This paper presents a study to ensure the minimum values of $R a$ and $R z$, and the maximum value of MRR when external cylindrical grinding by the PSI method. The experiments were performed according to the orthogonal Taguchi L9 matrix with the input parameters including workpiece speed, feed rate, and depth of cut in the conventional grinding machine. Analysis of experimental results by Pareto chart showed that the feed rate and the depth of cut most influence on $R a$ and $R z$, respectively. Feed rate and depth of cut all have a great influence on MRR. Meanwhile, the workpiece speed has a negligible effect on all three output parameters. The research results showed that to obtain the minimum values of $R a$ and $R z$, and maximum of MRR, the workpiece speed, feed rate, and depth of cut were $400 \mathrm{rev} / \mathrm{min} 37.7 \mathrm{~mm} / \mathrm{min}, 0.09 \mathrm{~mm} / \mathrm{rev}$, and $0.02 \mathrm{~mm}$, respectively.
\end{abstract}

\section{NOMENCLATURE}

$R a$ : The arithmetical mean deviation of the assessed profile

$R z$ : The minimum value of the profile maximum height

$n$ : Workpiece speed

$f:$ Feed rate

$a_{r}$ : Depth of cut

PSI: The preference selection index method

MRR: Material removal rate

GRA: Gray relational analysis method

MOORA: Multi-objective Optimization on the basis of ratio analysis

DEAR: The data envelopment analysis-based ranking

TOPSIS: Preference by similarity to the ideal solution

COPRAS: Complex proportional assessment

VIKOR: Vlsekriterijumska optimizacija i kompromisno resenje in Serbian

\footnotetext{
${ }^{1}$ Faculty of Mechanical Engineering, Hanoi University of Industry, Vietnam

${ }^{2}$ HaUI Institute of Technology - HIT, Hanoi University of Industry, Hanoi city, Vietnam

*E-mail: tiendung@ haui.edu.vn

https://doi.org/10.36897/jme/141607
} 


\section{INTRODUCTION}

Grinding is often chosen as a finish machining for the surface with a high requirement for accuracy and with small surface roughness [1]. Therefore, the parameters of the surface quality of the machine parts when grinding are especially interested. Several parameters of the surface properties of the part, such as wear resistance, fatigue strength, chemical corrosion resistance, and joint strength (for tight joints), are directly affected by surface roughness. Therefore, surface roughness is a very important parameter.

Many experimental studies have been carried out by many authors to determine the values of process parameters to ensure the small value of surface roughness. In all the studies as analysed below, the authors have built the experimental matrix according to the Taguchi method and then used the $\mathrm{S} / \mathrm{N}$ ratio analysis method to determine the optimal value. of the input parameters. When grinding $\mathrm{Al} / \mathrm{SiC}$ materials with aluminium oxide wheels, the authors of the study [2] selected cutting speed, workpiece velocity, feed rate and depth of cut as input parameters of the experimental process. experience. They have shown that to ensure minimum surface roughness, and the cutting speed is $2639 \mathrm{~m} / \mathrm{min}$, the part velocity is $26.72 \mathrm{~m} / \mathrm{min}$, the feed rate is $0.06 \mathrm{~m} / \mathrm{min}$, and the depth of cut is $0.3 \mathrm{~mm}$.

Reference [3] presented the optimization process of the cylindrical grinding of the EN353 steel by aluminium oxide grinding wheel. The authors of this study selected input parameters including wheel speed, feed rate and depth of cut. They have shown that, for minimum surface roughness, the wheel speed is $2000 \mathrm{rev} / \mathrm{min}(41.88 \mathrm{~m} / \mathrm{s})$, the feed rate is $125 \mathrm{~mm} / \mathrm{min}$, and the depth of cut is $0.14 \mathrm{~mm}$. The aluminium oxide wheel has also been used to grinding AISI 4150 steel [4]. In this study, the input parameters including wheel speed, abrasive grain size and depth of cut were selected. This study has shown that in order to have the minimum surface roughness when workpiece speed of $600 \mathrm{rev} / \mathrm{min}(43.35 \mathrm{~m} / \mathrm{min})$, the grain size of 100, and depth of cut of $0.02 \mathrm{~mm}$.

In reference [5], the cylindrical grinding process of EN 19 steel was conducted by an aluminium oxide grinding wheel. The wheel repair depth, feed rate (drag angle of the dresser) and the number of movements of the wheel repair head were selected as variables during the experiment. The obtained results showed that to achieve the minimum surface roughness value, the values of dressing depth of cut, dressing cross feed rate, drag angle of the dresser, and the number of passes was $20 \mu \mathrm{m}, 80 \mathrm{~mm} / \mathrm{min}, 500$, and 4, respectively. When using the aluminium oxide grinding wheel to cylindrical grind the $\mathrm{C} 40 \mathrm{E}$ steel, the optimal values of input parameters that were determined were workpiece velocity of 210 $\mathrm{m} / \mathrm{min}$, feed rate of $0.11 \mathrm{~mm} / \mathrm{rev}$, and depth of cut of $0.04 \mathrm{~mm}$. When machining with this set of optimal values, the surface roughness was the smallest [6].

In reference [7], the type of steel, workpiece speed, and depth of cut were selected as the input parameters to design the experimental matrix. Three steel types that were used in this study were EN19, EN24, and EN21, with the hardness of 40 HRC, 47 HRC, and 55 HRC, respectively. This study showed that the surface roughness was smaller when grinding the EN19 steel with the workpiece speed of $414 \mathrm{rev} / \mathrm{min}$ and depth of cut of $1 \mathrm{~mm}$. In another study, when grinding EN19 steel, the authors studied the minimum surface roughness when the cutting parameters were cutting velocity of $560 \mathrm{~m} / \mathrm{min}$, feed rate of $0.12 \mathrm{~mm} / \mathrm{rev}$, and cutting depth of $0.4 \mu \mathrm{m}$ [8]. In the grinding process of EN21 steel, if the grinding wheel speed 
was $1000 \mathrm{rev} / \mathrm{min}$, the feed rate was $0.12 \mathrm{~mm} / \mathrm{rev}$, and the depth of cut was $0.04 \mathrm{~mm}$, the surface roughness would be the smallest [9].

In reference [10], the workpiece velocity, depth of cut, and workpiece material (EN24 steel, EN31 steel, and EN353 steel) were chosen as the input parameters to design the experimental matrix. The obtained results showed that the surface roughness was smaller when grinding the EN353 steel with a cutting depth of $0.02 \mathrm{~mm}$ and a workpiece speed of $120 \mathrm{rev} / \mathrm{min}$ (workpiece diameter of $32 \mathrm{~mm}$ ). In this study, an aluminium oxide grinding wheel was also used in the experimental process. In addition to surface texture, MRR is also a parameter, is commonly chosen by the authors as an indicator to evaluate the efficiency of the grinding process in particular and the mechanical machining processes in general. This parameter was used to evaluate the productivity of a machining process [11].

The experimental studies to determine the machining parameters to ensure the maximum value of MRR has also been carried out by many authors. Some of the studies shown below also used the Taguchi method to design the experimental matrix, and then the S/N ratio analysis method was also used to solve the optimization problem. [12] The study has selected the wheel speed, workpiece speed, feed rate and depth of cut as input parameters when grinding EN15AM steel. Aluminium oxide grinding wheels were also used in this study. They eventually determined that if they wanted the maximum MRR, then the grinding wheel speed, workpiece speed, feed rate, and depth of cut were $1800 \mathrm{rev} / \mathrm{min}, 155 \mathrm{rev} / \mathrm{min}, 275 \mathrm{~mm} / \mathrm{rev}$, and $0.04 \mathrm{~mm}$, respectively. The optimization process when cylindrical grinding the AISI 316 steel using an aluminium oxide grinding wheel was performed and presented in reference [13]. The workpiece velocity, feed rate, and depth of cut is input parameters. In this study, the MRR was largest when the values of workpiece velocity, feed rate, and depth of cut were $560 \mathrm{~m} / \mathrm{min}, 0.13 \mathrm{~mm} / \mathrm{rev}$, and $0.005 \mathrm{~mm}$, respectively.

In reference [14], the optimization process was performed when the cylindrical grinding process of the AISI 1045 steel. The input parameters of grinding wheel speed, workpiece speed, grinding grain types (including Black aluminium oxide - A 60B, White aluminium oxide - A60W, and Green silicon carbide - SIC 60G), depth of cut, the concentration of the lubricant, and the number of passes. The results showed that $M R R$ was the largest value when using the A $60 \mathrm{~W}$ grinding grain, and the values of grinding wheel speed, workpiece speed, depth of cut, the concentration of the lubricant, and the number of passes were $2640 \mathrm{rev} / \mathrm{min}$, $250 \mathrm{rev} / \mathrm{min}, 0.025 \mathrm{~mm}, 5 \%$, and two times, respectively. When cylindrical grinding the OHNS steel (equivalent to AISI 0-1 steel) by aluminium oxide grinding wheel, to achieve the maximum value of MRR, the workpiece speed, depth of cut, number of passes were $150 \mathrm{rev} / \mathrm{min}, 0.02 \mathrm{~mm}$, and one time, respectively [15]. When cylindrical grinding the IS319 Brass material by aluminium oxide grinding wheel, to achieve the maximum value of MRR, the grinding process need to be performed with the grinding wheel of $11000 \mathrm{rev} / \mathrm{min}$ (grinding wheel diameter of $300 \mathrm{~mm}$ ), workpiece speed of $40 \mathrm{rev} / \mathrm{min}$ (workpiece diameter of $35 \mathrm{~mm}$ ), and cutting depth of $0.2 \mathrm{~mm}$ [16]. The optimal values of several parameters of grinding wheel dressing when using aluminium oxide grinding wheel to machine the 9CrSi steel were presented in reference [17]. This study showed that to achieve the maximum $M R R$ then the dressing feed rate was $1.4 \mathrm{~m} / \mathrm{min}$, the coarse dressing depth was $0.025 \mathrm{~mm}$, coarse dressing times was 1 , fine dressing depth was $0.005 \mathrm{~mm}$, fine dressing times was 3 , and nonfeeding dressing times was 5. 
The authors of the study [18] performed the grinding of AISI 316 L steel with silicon carbide grinding wheel. In this study they chose cutting speed, feed rate and depth of cut as variables that varied in each experiment. The analysed results showed that to achieve the maximum value of MRR, the values of cutting velocity, feed rate, and depth of cut were $200 \mathrm{~m} / \mathrm{min}, 0.3 \mathrm{~mm} / \mathrm{rev}$, and $0.3 \mathrm{~mm}$, respectively. And to achieve the minimum value of $R a$, the values of cutting velocity, feed rate, and depth of cut were $150 \mathrm{~m} / \mathrm{min}, 0.3 \mathrm{~mm} / \mathrm{rev}$, and $0.2 \mathrm{~mm}$, respectively.

The silicon carbide has been used to experiment with grinding EN19 steel [19]. The input parameters including workpiece speed, feed rate, depth of cut, and the workpiece hardness (30 HRC, $40 \mathrm{HRC}$, and $50 \mathrm{HRC}$ ). The obtained results showed that to achieve the maximum value of MRR, the workpiece speed, feed rate, depth of cut, and workpiece hardness were $247 \mathrm{rev} / \mathrm{min}, 0.18 \mathrm{~mm} / \mathrm{rev}, 0.04 \mathrm{~mm}$, and $30 \mathrm{HRC}$, respectively. And to achieve the minimum value of $R a$, the workpiece speed, feed rate, depth of cut, and workpiece hardness were $145 \mathrm{rev} / \mathrm{min}, 0.06 \mathrm{~mm} / \mathrm{rev}, 0.02 \mathrm{~mm}$, and $50 \mathrm{HRC}$, respectively. The experience of grinding EN8 steel with aluminium oxide wheels has also been studied [20]. Three input parameters including cooling lubricant oil types (water-soluble oil, pure oil, and pure water), workpiece speed, and depth of cut. The workpiece diameter was $100 \mathrm{~mm}$. The analysed results showed that to achieve the maximum value of MRR then the grinding process needs to be performed with the water-soluble oil, and the values of workpiece speed and depth of cut were $120 \mathrm{rev} / \mathrm{min}$ and $0.5 \mathrm{~mm}$, respectively. This set of optimal values was the same as the case the optimization criterion was the surface roughness.

The SCM440 steel is capable of withstanding large loads, good wear resistance, and high impact resistance. This steel type is often used to fabricate the components with variable loads such as motor drives, gears, plastic injection moulds, rolls, etc. These products are often required a cylinder grinding process as the final machining method for some surfaces. Equivalent symbols of this steel according to some standards as follows: JIS (Japan) SCM440; AISI (USA) - 4140; DIN (Germany) - 10083-3; GB (China) - 42CrMo; BS (UK) - 42CrMo4; NF (France) - 42CrMo4.

Several studies have been published on cylindrical grinding processes of this steel (or equivalent steel), such as determination of the values of the grinding wheel speed, workpiece speed, grind size, cutting depth, and concentration of coolant solution when grinding the AISI 4140 steel to ensure the minimum surface roughness [21]; determine the value of the workpiece speed, cutting depth and the number of slot when grinding AISI 4140 steel for minimum surface roughness [22]; Analysis of surface roughness when grinding the AISI 4140 steel [23], analysis of surface roughness when grinding SCM440 steel [24], analysis of surface roughness when grinding 42CrMo steel [25], etc. However, so far, the authors of this paper have not found any published research on the simultaneously optimizing process of the surface roughness and MRR when grinding this steel. Through the analysis of the above studies shows that:

First: the Taguchi method has been used a lot to design the experimental matrix. This is understandable as this method may only need to conduct a small number of experiments but allows for a wide selection of input parameters. In particular, this method that is the only experimental design method allows the selection of input parameters that are qualitative ones. However, the above studies also showed that if only using the Taguchi method, it is only 
possible to perform the single-objective optimization problem (through the analysis of the ratio $S / N)$.

In order to overcome this limitation, there have been some studies combining Taguchi with another method to solve the multi-objective optimization problem in cylindrical grinding processes, such as combining the Taguchi method and Gray relational analysis method (GRA) for solving the multi-objective Optimization in the grinding process of stainless steel [26], multi-objective Optimization in grinding process of aluminium alloy 6061-T4 [27], etc. In terms of the optimization method, up to now, there have been many multi-objective optimization methods that were introduced as in the above studies, such as the GRA method, MOORA method, DEAR method, TOPSIS method, COPRAS method, VIKOR method, PSI method, etc. In particular, the PSI method has been used to solve the multi-objective optimization problem in some studies such as multi-objective optimizing in the design of production systems [28]. Optimize the criteria of the computer software to serve human resource management [29], determine the best factors in choosing the positions to sell the used computers (premises rentals, location, number of customers) [30], multi-objective optimizing the turning process of AA7075 material [31], etc. However, up to now, there have not been any studies that have applied the PSI method to solving the multi-objective optimization problem in the grinding process in general and the cylindrical grinding process in particular.

Second: there are many parameters affecting surface roughness and MRR, such as cutting parameters, machining material type parameters, processing parameters, the grinding wheel dressing parameters, etc. In which cutting parameters are often chosen by the authors as input parameters when doing experimental research. This is also easily understood because the adjustment of the cutting parameters will be made simply by the operator who operates the machine.

Third: Aluminum oxide grinding wheel has been used a lot in the experimental processes. This is understandable because it is a low-cost grinding wheel, and it can be used to machine a variety of workpiece materials. However, through the above-mentioned studies, it also has been shown that the optimal values of the cutting parameters when grinding different materials are not the same. Thence, it shows that for each different material, there should be specific experimental and optimization studies. So, the optimal values of the cutting parameters can be determined to ensure the minimum value of surface roughness and maximum value of MRR.

In order to inherit the advantages of the published studies, as well as fill the several gaps in the contents that have not been implemented in the published studies. In this paper, the multi-objective optimization study in the cylindrical grinding process of SCM440 steel was carried out using an aluminium oxide grinding wheel. The experimental matrix was designed according to the Taguchi method, and the PSI method was used to solve multiobjective optimization problems. The goal of this study is to determine the values of the cutting parameters to ensure the minimum value of surface roughness and maximum value of MRR. The obtained results in this study are not only directly applied to production when using the aluminium oxide grinding wheel to grind the steel SCM440, but the methodology that was presented in this study can also be applied when studying the multi-objective optimization of other machining processes. 


\section{PSI METHOD}

PSI is a multi-objective optimization method that was first introduced in 2010. This is an approach based on the concept of "overall preference value of attributes". The outstanding feature of this method is the Optimization of the objectives without assigning weights to the criteria. This method is performed according to the following steps [32]:

Step 1: Determine the objectives.

Step 2: Create a decision matrix based on the available information.

Step 3: Normalize the attributes.

$$
\begin{array}{ll}
N_{i j}=\frac{x_{i j}}{x_{j}^{\max }} & \text { for criterion as large as better } \\
N_{i j}=\frac{x_{j}^{\min }}{x_{i j}} & \text { for criterion as small as better }
\end{array}
$$

Where $i$ is the ordinal number of the row in the matrix $(i=1 \div n), j$ is the ordinal number of the column in the matrix $(j=1 \div m), x_{i j}$ is the value of the criterion in row $i$ and column $j$. Step 4: Calculate the average values of normalized data.

$$
N=\frac{1}{n} \sum_{i=1}^{n} N_{i j}
$$

Step 5: Determine the preferred values from the average values.

$$
\varphi_{j}=\sum_{i=1}^{n}\left[N_{i j}-N\right]^{2}
$$

Step 6: Determine the deviation in the preferred value.

$$
\emptyset_{j}=\left[1-\varphi_{j}\right]
$$

Step 7: Determine the overall preferred value for the criteria.

$$
w_{j}=\frac{\emptyset_{j}}{\sum_{j=1}^{m} \emptyset_{j}}
$$

Step 8: Calculate the Preference Selection Index (PSI) of each solution.

$$
\theta_{j}=\sum_{j=1}^{m} x_{i j} \cdot w_{j}
$$

Step 9: Rank the solutions. Which solution has the largest value of $\theta_{i}$ is the best solution?

\section{EXPERIMENTAL METHOD}

\subsection{WORKPIECE MATERIAL}

The SCM440 workpieces were used in this study. The percentage of chemical components of some major elements of workpiece steel is determined by analysis on 
a spectrophotometer and presented in Table 1. These workpieces have the diameter and length of $30 \mathrm{~mm}$ and $250 \mathrm{~mm}$, respectively. And these workpieces were heat-treated to reach 52HRC hardness.

Table 1. Compositions of SCM440 steel

\begin{tabular}{|c|c|c|c|c|c|c|c|}
\hline Element & $\mathrm{C}$ & $\mathrm{Si}$ & $\mathrm{Mn}$ & $\mathrm{Cr}$ & $\mathrm{Mo}$ & $\mathrm{S}$ & $\mathrm{P}$ \\
\hline$\%$ & 0.42 & 0.26 & 0.68 & 1.02 & 0.22 & 0.022 & 0.018 \\
\hline
\end{tabular}

\subsection{GRINDING MACHINE AND GRINDING WHEEL}

The experiments were conducted in the conventional grinding machine (GU32x100S of Palmary Brand, Taiwan) as described in Fig. 1. Grinding wheels that were made in Hai Duong grinding wheel factory (Hai Duong grinding wheel company, Vietnam) was used in this study. The grinding wheel has the designation $C n 80-G-V-280-40-115-35 \mathrm{~m} / \mathrm{s}$, where $C n$ reflects the grinding wheel grain material as aluminium oxide, $G$ reflects the binder as ceramic, $V$ reflects the grinding wheel type as cylinder grinding wheel, 280 is the outer diameter of the grinding wheel, 40 is the thickness of the grinding wheel, 115 is the hole diameter of the grinding wheel. According to the manufacturer's recommendation, for this type of grinding wheel, the maximum usable cutting velocity is $35 \mathrm{~m} / \mathrm{s}$. The grinding wheel with grinding wheel grain material $(C n)$ and binder $(G)$ as the one used in this study is one of the most common grinding wheel types is used for grinding steel in a variety of grinding methods such as cylinder, surface, centreless grinding, etc. [33].

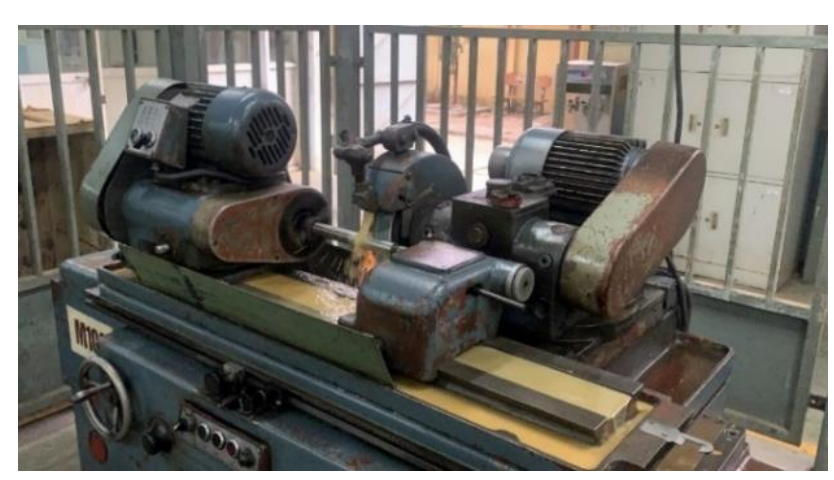

Fig. 1. Grinding machine

\subsection{EXPERIMENTAL DESIGN}

In this study, three parameters that were selected as the input parameters were workpiece speed $(n)$, feed rate $(f)$, and depth of cut $\left(a_{r}\right)$. Each parameter has three values corresponding to the three coding levels of $-1,0$, and 1 . The values of the input parameters were chosen according to the recommended range of the grinding wheel type using in this study for grinding the alloy steel [34], as presented in Table 2. The experimental matrix that was designed according to the Taguchi method was the orthogonal $L_{9}$ matrix, as listed in Table 3. 
Table 2. Input parameters and values at their level

\begin{tabular}{|l|c|c|c|c|c|}
\hline \multirow{2}{*}{ Parameter } & \multirow{2}{*}{ Symbol } & \multirow{2}{*}{ Unit } & \multicolumn{3}{c|}{ Value at level } \\
\cline { 3 - 6 } & & & 1 & 2 & 3 \\
\hline Workpiece speed & $n$ & $\mathrm{rev} / \mathrm{min}$ & 400 & 600 & 800 \\
\hline Feed rate & $f$ & $\mathrm{~mm} / \mathrm{rev}$ & 0.05 & 0.075 & 0.09 \\
\hline Depth of cut & $a_{r}$ & $\mathrm{~mm}$ & 0.01 & 0.015 & 0.02 \\
\hline
\end{tabular}

Table 3. Orthogonal matrix $L_{9}$

\begin{tabular}{|c|c|c|c|c|c|c|}
\hline \multirow{2}{*}{ No. } & \multicolumn{3}{|c|}{ Code value } & \multicolumn{3}{c|}{ Actual value } \\
\cline { 2 - 7 } & $n$ & $f$ & $a_{p}$ & $\begin{array}{c}n \\
(\mathrm{rev} / \mathrm{min})\end{array}$ & $\begin{array}{c}f \\
(\mathrm{~mm} / \mathrm{rev})\end{array}$ & $\begin{array}{c}a_{r} \\
(\mathrm{~mm})\end{array}$ \\
\hline 1 & 1 & 1 & 1 & 400 & 0.05 & 0.01 \\
\hline 2 & 1 & 2 & 2 & 400 & 0.075 & 0.015 \\
\hline 3 & 1 & 3 & 3 & 400 & 0.05 & 0.015 \\
\hline 4 & 2 & 1 & 2 & 600 & 0.075 & 0.02 \\
\hline 5 & 2 & 2 & 3 & 600 & 0.09 & 0.01 \\
\hline 6 & 2 & 3 & 1 & 600 & 0.05 & 0.02 \\
\hline 7 & 3 & 1 & 3 & 800 & 0.075 & 0.01 \\
\hline 8 & 3 & 2 & 1 & 800 & 0.09 & 0.015 \\
\hline 9 & 3 & 3 & 2 & 800 & & \\
\hline
\end{tabular}

\subsection{MEASUREMENT SYSTEM}

The machining surface roughness ( $R a$ and $R z$ ) were measured using SJ-301 surface tester of Mitutoyo (Japan). The machine code is 178-953-2, the stylus tip code is 178-390, and the stylus tip radius is $5 \mu \mathrm{m}$. The standard length of each measurement was fixed at 0.8 $\mathrm{mm}$. Each experimental piece was measured at least three times. Surface roughness at each experiment is calculated by the average of the successive measurements. The reason for this study to choose both $R a$ and $R z$ to evaluate surface roughness is because $R a$ and $R z$ are two of the most popular parameters to evaluate surface roughness. However, since there is no mathematical relationship between $R a$ and $R z$, it is possible that some surface has large $R a$, but $R z$ is small and vice versa. Therefore, to have a more comprehensive view of surface roughness, it is necessary to examine both of these parameters [35,36]. $M R R$ is calculated as the material removal per minute. This parameter is calculated by subtracting the volume of the workpiece before grinding to the volume from the workpiece after grinding and dividing it by the grinding time. Where the grinding time is calculated by the length of the grinding divided by the displacement speed of the grinding wheel (the feed rate).

\subsection{GRINDING CONDITIONS}

The experiments were performed in machining conditions as follows: The spindle speed was $1750 \mathrm{rev} / \mathrm{min}$ (corresponding to $25.65 \mathrm{~m} / \mathrm{s}$ ); the grinding wheel is dressed by a dressing tool with one diamond grain, the dressing depth is $0.01 \mathrm{~mm}$, the dressing feed rate is $120 \mathrm{~mm} / \mathrm{min}$; the cooling lubricant that is used in the experimental process is industrial oil N-600 (made in Vietnam) with the concentration of $12 \%$ and the flow of 16 litres/min. These values have been selected according to the grinding wheel manufacturer's recommendation. 


\section{RESULTS AND DISCUSSION}

The experiments were carried out in the order of the experiments as listed in Table 3, measuring the surface roughness of machining parts and calculating the MRR for each experiment measured and calculated results are presented in Table 4.

Table 4. Experimental results

\begin{tabular}{|c|c|c|c|c|c|c|}
\hline No. & $n(\mathrm{rev} / \mathrm{min})$ & $\begin{array}{c}f \\
(\mathrm{~mm} / \mathrm{rev})\end{array}$ & $a_{r}(\mathrm{~mm})$ & $R a(\mu \mathrm{m})$ & $R z(\mu \mathrm{m})$ & $\mathrm{MRR}\left(\mathrm{mm}^{3} / \mathrm{min}\right)$ \\
\hline 1 & 400 & 0.05 & 0.01 & 0.51 & 2.06 & 82.439 \\
\hline 2 & 400 & 0.075 & 0.015 & 0.73 & 4.52 & 105.976 \\
\hline 3 & 400 & 0.09 & 0.02 & 0.59 & 4.24 & 169.533 \\
\hline 4 & 600 & 0.05 & 0.015 & 0.38 & 1.77 & 70.650 \\
\hline 5 & 600 & 0.075 & 0.02 & 0.42 & 3.53 & 141.277 \\
\hline 6 & 600 & 0.09 & 0.01 & 0.76 & 2.12 & 84.795 \\
\hline 7 & 800 & 0.05 & 0.02 & 0.39 & 2.35 & 94.185 \\
\hline 8 & 800 & 0.075 & 0.01 & 0.59 & 1.97 & 70.662 \\
\hline 9 & 800 & 0.09 & 0.015 & 0.64 & 3.18 & 127.171 \\
\hline
\end{tabular}

Figure 2 present the Pareto graphs about the influence of the input parameters on the output parameters with the chosen significance level by 0.05 . Then the limit line of the Parate chart (red line) is equal to 2.571. The plot (horizontal gray line) of a parameter that exceeds this limit is considered to have a significant effect on the output. Accordingly, it is shown in Fig. 2a that the feed rate is a parameter that has a significant influence on $R a$. This means that this parameter has a significant effect on $R a$. The workpiece speed and cutting depth have a negligible effect on $R a$. For $R z$, only the depth of cut that is the parameter has a significant influence on $R z$, as shown in Fig. 2b. This can be explained that when the feed rate changes, it will change the degree of the scratching of the grinding grains on the workpiece surface, thereby affecting on the surface roughness. This is an issue that was discussed in several published studies $[33,37]$. When changing the depth of cut, it will change the amount of heat that was generated and transferred to the workpiece during the grinding process. The change in the amount of heat transferred to the workpiece will change the plastic deformation of the surface metal layer, which is the reason for the change in surface roughness $[38,39]$.

The two parameters, including cutting depth and the feed rate, are directly related to the volume of the material removed from the workpiece surface in a unit of time. In this case, if vibration and elastic deformation (of the grinding wheel and workpiece) arising from the grinding process are ignored, the depth of cut is the thickness of the removed material. At the same time, the feed rate has a direct influence on the time to complete the entire length of the workpiece. Therefore, the depth of cut and the feed rate has a significant influence on the MRR. This result is completely consistent when observing Fig. 2c. The results in this figure also showed that the workpiece velocity has a negligible effect on the MRR.

As such, it is clear that the influence degrees of the input parameters on the output parameters are not the same. Therefore, it is very difficult to select the values of the input 
parameters to ensure the objectives of the output parameters (minimum $R a$ and $R z$, largest $M R R$ ). On the other hand, observing data in Table 4 shows that: MRR has the largest value in experiment \# 3, while $R a$ has the smallest value in experiment \# 4, while $R z$ has the smallest value in experiment \# 4. Therefore, it is necessary to perform multi-objective Optimization to find the experiment where MRR is considered to be "maximum", $R a$ and $R z$ are considered to be "minimum".

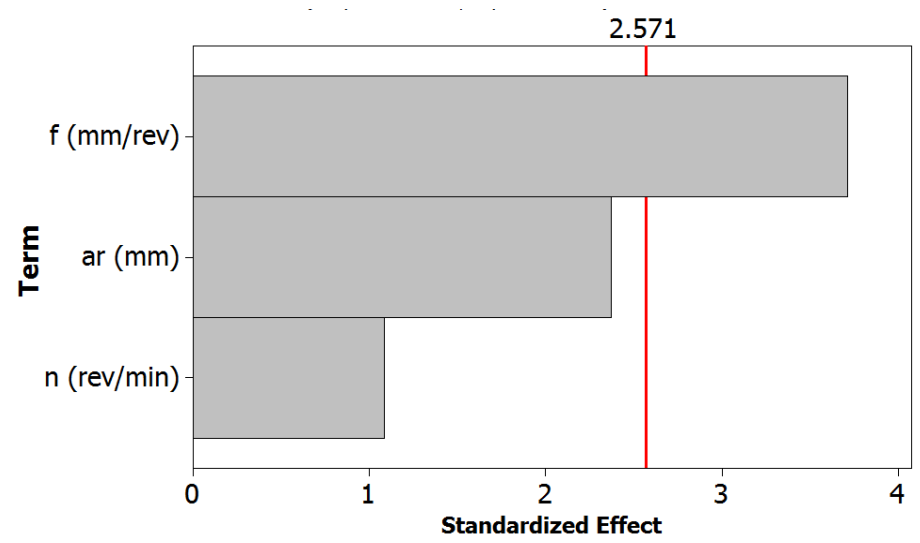

a. Influence of input parameters on $R a$

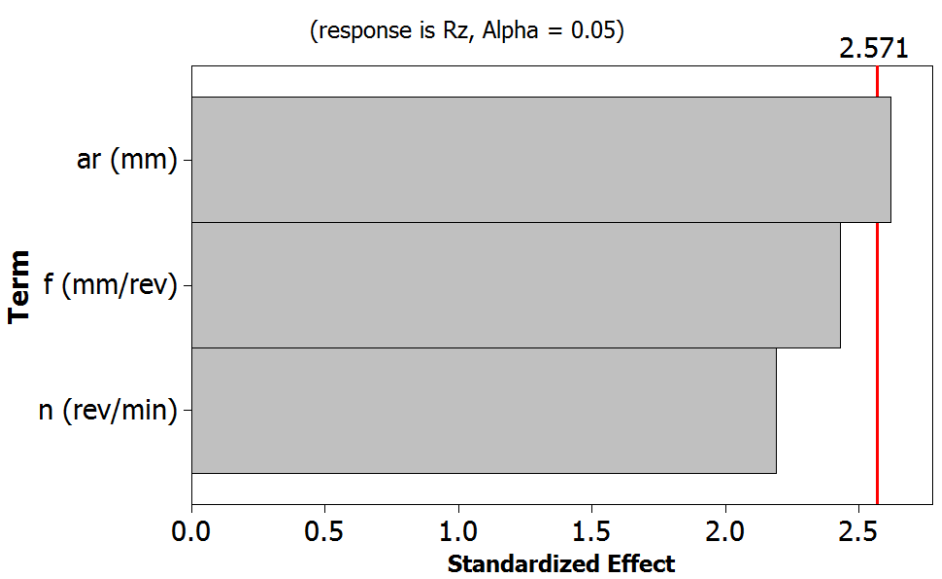

b. Influence of input parameters on $R z$

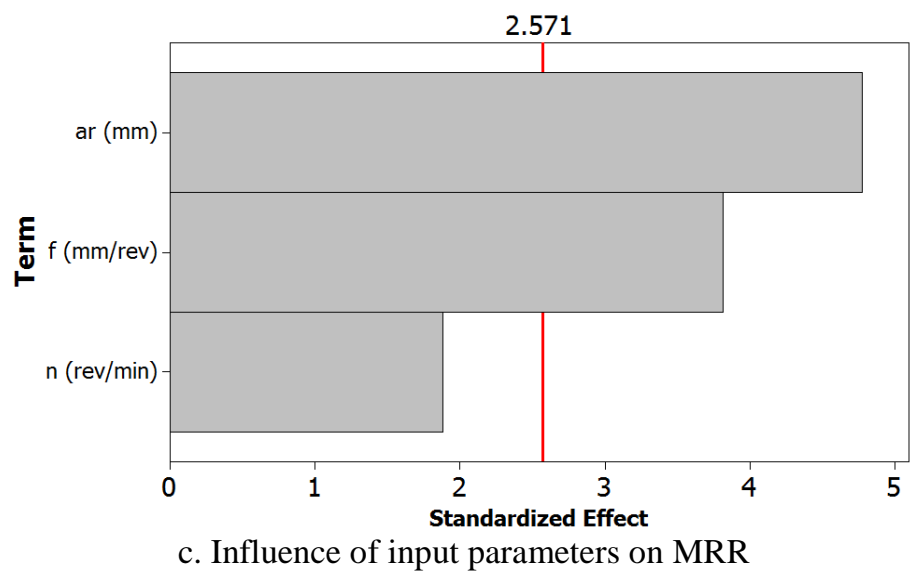

Fig. 2. Pareto diagram about Influence of the input parameters on the output parameters 


\section{MULTI-OBJECTIVE OPTIMIZATION USING PSI METHOD}

The performing steps according to the PSI method were presented in detail in Chapter 2. The application of the PSI method in this study was performed as follows.

Step 1: Determine the objectives. The objectives of this study are the determination of the best solution in the solutions as listed in Table 4. At that solution (experiment), $R a$ and $R z$ are considered "minimum", and MRR is considered "largest".

Step 2: Create a decision matrix based on the available information. From the data in Table 4, the last three columns form a 9-row 3-column matrix, which is the matrix where we need to identify the row considered "best" in 9 rows.

Step 3: The standardization values of the attributes were calculated by Eq. (1) and Eq. (2). These values were calculated and listed in Table 5.

Step 4: The average values of normalized data were calculated by Eq. (3). These values were also listed in Table 5.

Step 5: Determine the preferred values from the average values by Eq. (4): $\varphi_{\mathrm{Ra}}=0.2933$; $\varphi_{\mathrm{Rz}}=0.4099 ; \varphi_{\mathrm{MRR}}=0.3259$.

Step 6: Determine the deviation in the preferred value by Eq. $(5): \varnothing_{\mathrm{Ra}}=0.7067 ; \varnothing_{\mathrm{Rz}}=$ $0.5901 ; \varnothing_{\mathrm{MRR}}=0.6741$.

Step 7: Determine the overall preferred value for the criteria by Eq. (6): $\mathrm{w}_{\mathrm{Ra}}=0.3586$; $\mathrm{W}_{\mathrm{Rz}}=0.2994 ; \mathrm{w}_{\mathrm{MRR}}=0.3420$.

Step 8: Calculate the Preference Selection Index $\theta$ (PSI) of each solution by Eq. (7). These calculated results were presents in Table 6 .

Step 9: Rank the solutions as presented in Table 6.

Table 5. Standardization value of the attributes

\begin{tabular}{|l|c|c|c|c|c|c|}
\hline No. & $R a(\mu \mathrm{m})$ & $R z(\mu \mathrm{m})$ & $\mathrm{MRR}\left(\mathrm{mm}^{3} / \mathrm{min}\right)$ & $N_{R a}$ & $N_{R z}$ & $N_{\mathrm{MRR}}$ \\
\hline 1 & 0.51 & 2.06 & 82.439 & 0.7451 & 0.8592 & 0.4863 \\
\hline 2 & 0.73 & 4.52 & 105.976 & 0.5205 & 0.3916 & 0.6251 \\
\hline 3 & 0.95 & 4.24 & 169.533 & 0.6441 & 0.4175 & 1.0000 \\
\hline 4 & 0.38 & 1.77 & 70.650 & 1.0000 & 1.0000 & 0.4167 \\
\hline 5 & 0.59 & 3.53 & 141.277 & 0.9048 & 0.5014 & 0.8333 \\
\hline 6 & 0.76 & 2.12 & 84.795 & 0.5000 & 0.8349 & 0.5002 \\
\hline 7 & 0.39 & 2.35 & 94.185 & 0.9744 & 0.7532 & 0.5556 \\
\hline 8 & 0.59 & 1.97 & 70.662 & 0.6441 & 0.8985 & 0.4168 \\
\hline 9 & 0.64 & 3.18 & 127.171 & 0.5938 & 0.5566 & 0.7501 \\
\hline Mean & \multicolumn{7}{|l}{} & 0.6691 & 0.6903 & 0.6205 \\
\hline
\end{tabular}

Table 6. Values of $\theta$ in PSI and ranking

\begin{tabular}{|c|c|c|c|c|c|}
\hline No. & $R a(\mu \mathrm{m})$ & $R z(\mu \mathrm{m})$ & $M R R\left(\mathrm{~mm}^{3} / \mathrm{min}\right)$ & $\theta$ & Ranking \\
\hline 1 & 0.51 & 2.06 & 82.439 & 28.9938 & 7 \\
\hline 2 & 0.73 & 4.52 & 105.976 & 37.8589 & 4 \\
\hline 3 & 0.59 & 4.24 & 169.533 & 59.4613 & 1 \\
\hline 4 & 0.38 & 1.77 & 70.650 & 24.8285 & 9 \\
\hline
\end{tabular}




\begin{tabular}{|l|l|l|l|l|l|}
\hline 5 & 0.42 & 3.53 & 141.277 & 49.5242 & 2 \\
\hline 6 & 0.76 & 2.12 & 84.795 & 29.9072 & 6 \\
\hline 7 & 0.39 & 2.35 & 94.185 & 33.0547 & 5 \\
\hline 8 & 0.59 & 1.97 & 70.662 & 24.9678 & 8 \\
\hline 9 & 0.64 & 3.18 & 127.171 & 44.6741 & 3 \\
\hline
\end{tabular}

From the ranked results in Table 6, it shows that experiment \# 3 is the best experiment of 9 experiments, besides that experiment \# 4 is the worst experiment. In experiment \# 3, it is clear that $M R R$ has the largest value in 9 experiments $\left(M R R=169,533 \mathrm{~mm}^{3} / \mathrm{min}\right), R a$ is $0.59 \mu \mathrm{m}$, smaller than the value of $R a$ in experiment \# 2, \# 6 and \# $9, R z$ is $4.24 \mu \mathrm{m}$, this value is quite large, it is only smaller than the value of $R z$ in experiment \# 2. Although $R a$ and $R z$ in experiment \# 3 are not the minimum values in 9 experiments, for the purpose of multiobjective Optimization, it can be confirmed that experiment \# 3 is the "best" solution.

\section{CONCLUSION}

In this study, the cylindrical grinding experiments were performed to machine the SCM440. Three parameters that were chosen as the input parameters were workpiece speed, feed rate, and depth of cut. $R a, R z$, and MRR were selected as the output parameters of the experimental process. The analysing process of experimental data has determined the influence degree of input parameters on the output parameters. PSI method was applied to solve the multi-objective optimization problem. Several conclusions are drawn from this study as follows:

1. The workpiece speed has a negligible influence on all three parameters, including $R a$, $R z$, and MRR. The feed rate has a large effect on $R a$ and MRR but has a negligible effect on $R z$. The depth of cut has a great influence on $R z$ and MRR but has a negligible effect on $R a$.

2 . The cutting parameters that were applied to simultaneously obtain the minimum value of $R a$, the minimum value of $R z$, and the maximum of MRR were workpiece of $400 \mathrm{rev} / \mathrm{min}$, feed rate of $0.09 \mathrm{~mm} / \mathrm{rev}$, and cutting depth of $0.02 \mathrm{~mm}$.

3. PSI is a quite simple multi-objective optimization method. When applying this method, only need to perform through nine simple mathematical equations sequentially. Therefore, this method has been applied in several studies. This is the first time that the PSI method was successfully applied to solve the multi-objective Optimization in the cylindrical grinding process. This is a method that promises to be successful when applied to solve the multiobjective problem in different machining methods.

4. This study only shows the best value among the surveyed value levels of the input parameters. In fact, the value at a level that is considered best may not be the best value for that parameter. In addition, many parameters affecting the efficiency of the grinding process have not been considered, such as grinding wheel dressing parameters, cooling and lubrication parameters, etc. These are necessary issues to be performed in the next research to complete the evaluation of the grinding process of the SCM440 steel. 


\section{REFERENCES}

[1] NGUYEN N.-T., TRUNG D.D., 2021, Investigation of the Surface Roughness in Infeed Centerless Grinding of SCM435 Steel, International Journal of Automation Technology, 15/1, 123-130.

[2] THIAGARAJAN C., RANGANATHAN S., SHANKA P., 2015, Cylindrical Grinding Process Parameters Optimization of Al / Sic Metal Matrix Composites, International Journal of Scientific \& Engineering Research, 6/2, 738-743.

[3] BHAVSAR T., NOKALJE A.M., 2020, Optimization of Cylindrical Grinding Process Parameters for EN353 Steel Using Taguchi Technique, International Journal for Research in Applied Science \& Engineering Technology, 8/11, 225-231.

[4] SINGLA S., DEV D.K., 2018, Optimization of Cylindrical Grinding Process Parameters for Heat Treated AISI 4150 Steel, International Journal on Theoretical and Applied Research in Mechanical Engineering, 7/2-3, 5-10.

[5] MOIHITE D.D., TIWARI N., SONTAKKE S., MISHRA U., 2017, Modelling and Optimization of Dressing Parameters of CNC Cylindrical Grinding Wheel for Minimum Surface Roughness, International Journal of Engineering Research and General Science, 5/4, 102-111.

[6] KUMAR N., TRIPATHI H., GANDOTRA S., 2015, Optimization of Cylindrical Grinding Process Parameters on C4OE Steel Using Taguchi Technique, International Journal of Engineering Research and Applications, 5/1, 100-104.

[7] PANTHAGI R.K., Naduvinamani V., 2017, Optimization of Surface Roughness in Cylindrical Grinding Process, International Journal of Applied Engineering Research, 12/18, 7350-7354.

[8] SANGALE S.S., DONGARE A.D., 2019, Optimization of the Parameter in Cylindrical Grinding of Mild Steel Rod (EN19) by Taguchi Method, International Journal of Creative and Innovative Research in All Studies, 4/4, 66-73.

[9] GURUCHANDRA N., REDDY B.A.K., REDDY M.C.S., 2017, Optimization of Cylindrical Grinding Process Parameters on Material Removal Rate of EN21AM Steel, International Journal of Engineering Research \& Technology, 6/6, 623-631.

[10] GEORGE L.P., JOB K.V., CHANDRAN I.M., 2013, Study on Surface Roughness and its Prediction in Cylindrical Grinding Process Based on Taguchi Method of Optimization, International Journal of Scientific and Research Publications, 3/5, 1-5.

[11] NGUYEN N.-T., TRUNG D.D., 2020, A Study on the Surface Grinding Process of the SUJ2 Steel Using CBN Slotted Grinding Wheel, AIMS Materials Science, 7/6, 871-886.

[12] KUMAR S., BHATIA O.S., 2015, Review of Analysis \& Optimization of Cylindrical Grinding Process Parameters on Material Removal Rate of En15AM Steel, IOSR Journal of Mechanical and Civil Engineering, 12/4, 35-43.

[13] MEKALA K., CHANDRADAS J., CHANDRASEKARAN K., KANNAN T.T.M., RAMESH E., BABU R.N., 2014, Optimization of Cylindrical Grinding Parameters of Austenitic Stainless Steel Rods (AISI 316) by Taguchi Method, International Journal of Mechanical Engineering and Robotics Research, 3/2, 208-215.

[14] SINGH T., GOYAL K., KUMAR P., 2015, Effect of Process Parameters for Optimum Material Removal Rate Cylindrical Grinding of AISI 1045 Steel, Journal of Mechanical Engineering, 44/2, 100-104.

[15] SRIDHAR M.M.J., MANICKAM M., KALAIYARASAN V., 2014, Optimization of Cylindrical Grinding Process Parameters of OHNS Steel (AISI 0-1) Rounds Using Design of Experiments Concept, International Journal of Engineering Trends and Technology, 17/3, 109-114.

[16] UPADHYAY G., RAMPRASAD, HASSAN K., 2015, Optimization of Metal Removal Rateon Cylindrical Grinding for is 319 Brass Using Taguchi Method, International Journal of Engineering Research and Applications, 5/6, 63-68.

[17] HUNG L.X., HONG T.T., KY L.H., TUNG L.A., NGA N.T.T., PI V.N., 2018, Optimum Dressing Parameters for Maximum Material Removal Rate When Internal Cylindrical Grinding Using Taguchi Method, International Journal of Mechanical Engineering and Technology, 9/12, 123-129.

[18] AHMED K.N., AHER A.S., 2020, A Review on Optimization of Process Parameter in Cylindrical Grinding of Austenitic Stainless Steel Rod (AISI 316 L) by Taguchi Method, Mukt Shabd Journal, 9/6, 2346-2352.

[19] PATIL K.R., KARANDE R.J., MOHITE D.D., JADHAV V.S., 2017, Modeling and Optimization of Cylindrical Grinding Parameters for MRR and Surface Roughness, International Journal of Engineering Sciences \& Research Technology, 6/4, 498-503.

[20] THAKOR S.P., PATEL D.M., 2014, An Experimental Investigation on Cylindrical Grinding Process Parameters for En 8 Using Regression Analysis, International Journal of Engineering Development and Research, 2/2, 2486-2491.

[21] SINGH K., KUMAR P., GOYAL K., 2014, To Study the Effect of Input Parameters on Surface Roughness of Cylindrical Grinding of Heat Treated AISI 4140 Steel, American Journal of Mechanical Engineering, 2/3, 58-64. 
[22] KOKLU U., 2013, Optimization of Machining Parameters in Interrupted Cylindrical Grinding Using the GreyBased Taguchi Method, International Journal of Computer Integrated Manufacturing, 26/8, 696-702.

[23] STIPKOVIK M.A., BORDINASSI E.C., FARIAS A.D., DELIJAICOV S., 2017, Surface Integrity Analysis in Machining of Hardened AISI 4140 Steel, Materials Research, 20/2, 387-394.

[24] KWAK J.-S., SIM S.-B., JEONG Y.-D., 2006, An Analysis of Grinding Power and Surface Roughness in External Cylindrical Grinding of Hardened SCM440 Steel Using the Response Surface Method, International Journal of Machine Tools \& Manufacture, 46, 304-312.

[25] OZDEMIR M., KAYA M.T., AKYILDIZ H.K., 2020, Analysis of Surface Roughness and Cutting Forces in Hard Turning of 42CrMo4 Steel Using Taguchi and RSM Method, Mechanika, 26/3, 231-241.

[26] RUDRAPATI R., BANDYOPADHYAY A., PAL P.K., 2013, Multi-Objective Optimization in Traverse Cut Cylindrical Grinding, Advanced Materials Manufacturing \& Characterization, 3/1, 335-339.

[27] RUDRAPATI R., BANDYOPADHWAY A., PAL P.K., 2018, Parametric Optimization of Cylindrical Grinding Process through Hybrid Taguchi Method and RSM Approach using Genetic Algorithm, Iranian Journal of Mechanical Engineering, 19/1, 34-62.

[28] ATTRI R., GROVER S., 2015, Application of Preference Selection Index Method for Decision Making Over the Design Stage of Production System Life Cycle, Journal of King Saud University - Engineering Sciences, 27/2, 207-216.

[29] VAHDANI B., MOUSAVI S.M., EBRAHIMNEJAD S., 2014, Soft Computing-Based Preference Selection Index Method for Human Resource Management, Journal of Intelligent \& Fuzzy Systems, 26, 393-403.

[30] SAHIR S.H., AFRIANI J., GINTING G., FACHRI B., SIREGAR D., et al., 2018, The Preference Selection Index Method in Determining the Location of Used Laptop Marketing, International Journal of Engineering \& Technology, 7/3-4, 260-263.

[31] PRASAD R.V., RAO C.M., RAJU B.N., 2018, Application of Preference Selection Index (PSI) Method for The Optimization of the Turning Process Parameters, International Journal of Modern Trends in Engineering and Research, 5/5, 140-144.

[32] MANIYA K., BHATT M.G., 2010, A Selection of Material Using a Novel Type Decision-Making Method: Preference Selection Index Method, Materials and Design, 31, 1785-1789.

[33] MALKIN S., GUO C., 2008, Grinding Technology: Theory and Applications of Machining with Abrasives, Industrial press, New York.

[34] LONG B.T., LUC T.T., TUY T.S., 2001, Material Processing Principles, Science and technics publishing House, Hanoi.

[35] SON N.H., TRUNG D.D., 2020, An Experimental Study on Surface Roughness - Applied to Determine the Optimal Value of Cutting Parameters when Milling 40Cr Steel, International Journal of Mechanical and Production Engineering Research and Development, 10/2, 101-110.

[36] PATHAK B.N., SAHOO K.L., MISHRA M., 2013, Effect of Machining Parameters on Cutting Forces and Surface Roughness in Al-(1-2) Fe-1V-1Si Alloys, Materials and Manufacturing Processes, 28, 463-469.

[37] MARINESCU I.D., HITCHINER M.P., UHLMAN E., ROWE W.B., INASAKI I., 2006, Handbook of Machining with Grinding Wheels, CRC Press.

[38] TRUNG D.D., THIEN N.V., NGUYEN N.-T., 2021, Application of TOPSIS Method in Multi-Objective Optimization of the Grinding Process Using Segmented Grinding Wheel, Tribology in Industry, 43/1, 12-22.

[39] GUHA S., PROTIM D.P., CHAKRABPRTY S., 2019, Improvement in the Performance with Less Stiff Air Layer Formation Around the Rubber Tube-Pasted Grinding Wheel, Proceedings of the Institution of Mechanical Engineers, Part C, Journal of Mechanical Engineering Science, 233/15, 5175-5189. 